\title{
Makro İhtiyati Tedbirler Çerçevesinde Tüketici Kredilerine İlişkin Düzenlemelerin Etkinliği: Türkiye Örneği
}

\author{
Efficiency of Regulations Regarding Consumer Credits In Macro-Prudential \\ Framework: Case of Turkey
}

Hasan Ferit YÜCEYILMAZ1 ${ }^{1}$, Onur ALTIN², K. Batu TUNAY³

\begin{abstract}
ÖZET
2007-2008 küresel krizi öncesi düzenleme sistemi bankaların tek tek güvenli olmasının tüm sistemi güvenli hale getirdiği varsayımı üzerine kurulmuştu. $\mathrm{Bu}$ durum küresel finansal kriz sonrası değişmiş ve makro ihtiyati yaklaşımların sisteme entegre edilmesi ve var olan mikro ihtiyati düzenleme sisteminin desteklenmesi gerektiği ortaya çıkmıştır. Bu kapsamda, bankacılık sektörünün döngü yönlü hareket etmesi ve bu davranışıyla sistemik riskleri arttırması döngü karşıtı finansal düzenlemeleri hızla gündemin ön sıralarına taşımıştır. Bu çalışma, Türkiye'de tüketici kredilerinin artış hızını kontrol altına almak maksadıyla 2011 ve 2013 yıllarında BDDK tarafından yapılan düzenleme değişikliklerinin etkinliğini sınamak amacıyla yapılmıştır. Bu amaçla kurulan modeller En Küçük Kareler (EKK) ve Genelleştirilmiş Momentler Yöntemi (GMY) tahmin edicileri kullanılarak tahminlenmiştir. Yapılan tahminlerden elde edilen bulgular; döngü karşıtı düzenleme değişikliklerinin, BDDK'nın istediği şekilde, tüketici kredileri üzerinde sınırlayıcı anlamlı bir etkisinin olduğunu göstermektedir.
\end{abstract}

Anahtar kelimeler: Finansal kriz, mikro ve makro ihtiyati kurallar, sistemik risk, döngü yönlülük, döngü karşıtı finansal düzenlemeler.

\section{Gíriş}

2008 yılında başlayan finansal krizde, sisteme yaygın riskleri anlamlandırmada eksikliklerin olduğu ve özellikle finans kurumlarının bilançolarında aşırı riskli finansal varlıklardan kaynaklanan yapının finansal sistem içinde büyümesinin bütüncül bakış açısı ile yeterince değerlendirilemediği düşünülmektedir. Küresel finansal dengesizliklerin

\begin{abstract}
Before 2007-2008 global financial crisis, regulation system was based on the assumption that making each bank safe would make the banking system safe. After the crisis, it came out that macro prudential perspective was to be integrated and existing micro prudential regulation system should be supported. In this context, banking sector's procyclicality and by this behavior leading the way to increasing systemic risks has put swiftly countercyclical financial regulations on top of the agenda. This paper is aimed to test the effect of regulation changes made by Turkish banking authority (BDDK), put in effect in 2011 and 2013, in order to stabilize increase in consumer credits. Models established for this aim had estimated by using Ordinary Least Squers (OLS) and Generalized Method of Moments estimators. Evidences obtained from estimates have shown that countercyclical regulation changes has a significant restricting effect on consumer credits as admired by Turkish banking authority.
\end{abstract}

Keywords: Financial crisis, micro and macro prudential rules, systemic risk, procyclicality, countercyclical financial regulations. 
denetim açısından makro ihtiyati kuralların uygulanması konusunda ortak bir uzlaşının oluşmaya başladığı görülmektedir. Bu uzlaşının en önemli göstergesi olarak Basel II üzerine kurulan Basel III gösterilebilir. Bilindiği üzere Basel III küresel sermaye ve likidite standartları getirmektedir. Dolayısıyla Basel III'ün çerçevesini Basel II'nin üzerine konulan makro ihtiyati önermeler oluşturmaktadır. Ayrıca bazı ülkelerin bankacılık sektöründe kullanılan (örneğin İspanya) ileriye dönük karşılık ayırma düzenlemeleri, küresel olarak önemle üzerinde durulan sistemik önemli bankalara (SIFI) yönelik geliştirilen ek yükümlülükler ve döngü karşıtı finansal düzenlemeler makro ihtiyati politikalar olarak gündemde yer almaktadırlar.

Politika tartışmaları bir yandan makro ihtiyati araçların kullanımı ve etkinliği üzerinde yoğunlaşırken diğer yandan bunların makroekonomik sonuçları ve para politikası ilişkileri de tartışma konusu olmaktadır. Literatürde, makro intiyati politikalar para politikasını destekleyen politikalar olarak görülmekte olup daha dayanıklı ve daha az döngü yönlü hareket eden bankacılık sisteminin para politikasının etkinliğini arttıracağı savunulmaktadır. Diğer bir değişle, makro intiyati politikaların bankacılık sisteminin dayanıklılığını artırarak ekonomide aşırı ısınmayı önleme konusunda etkin olduğu öne sürülmektedir. Bu doğrultuda, bazı ülkelerdeki kredi-değer oranı kısıtlamalarının (örneğin Türkiye'de bankalar tarafından tahsis edilebilecek azami konut kredisi miktarı taşınmazın ekspertiz değerinin \%80'ini geçemez.) ve özel provizyon gereksinimlerinin, varlık fiyatı enflasyonunu ve gayri menkul sektöründe kredi gelişimini kontrol altına almaya yardımcı olduğu gösteren çalışmalar mevcuttur. Türkiye gibi gelişmekte olan ülkeler bu süreçte makro bakış açılarını sistemlerine entegre etme çabası göstermektedirler. Bu kapsamda, finansal istikrarsızlık yaratabilecek sistemik riskler tespit edilerek finansal düzenlemeler yoluyla bu risklerin giderilmesi hedeflenmektedir.

Bu çalışmanın temelini oluşturan tüketici kredileri, çağdaş bankacılık sisteminde, çok sayıda kişiye küçük miktarda verilen krediler sayesinde riskin tabana yayılması ve risk çeşitlendirmesi açısından önemli bir yere sahiptir. Teorik olarak değerlendirildiğinde, hanehalkının gelecek döneme konu olacak intiyaçlarını / tüketimlerini şimdiki zamanda yapmasına olanak sağlayan tüketici kredileri bu yönden ekonomiyi etkilemektedir. Bu durumda, bankalar hanehalkının gelecek dönem gelirlerini teminat saymakta ve tüketiciler de finanse ettikleri tüketimleri için gelecek dönemde elde edecekleri gelirlerinin bir kısmından feragat etmektedirler. Dolayısıyla tüketici kredileri şimdiki zamandaki talebi artırdığı için ilk aşamada büyüme göstergelerinde hızlı bir yükselişe neden olmaktadır.

Bununla birlikte, kredi ile finanse edilecek ihtiyaçların belirlenmesinde hanehalkının rasyonel davranıştan uzaklaştığı görülmektedir. Günümüz teknolojisinin de katkısıyla krediye erişiminin kolaylaşması, hanehalkında tüketim çılgınlığına sebebiyet vermekte ve kredi ile finanse ettikleri rasyonel olmayan tüketim harcamaları, toplumda bir kredi / borç sarmalına dönüşmekte ve hanehalkının gelecek dönem tüketimi ve refahına doğrudan olumsuz etki etmektedir. Bu durum, uzun dönemde talep mekanizmasında yavaşlamaya, ekonomik istikrarın bozulmasına ve uzun süreli yaşanan ekonomik resesyonlara sebep olmaktadır. Bankacılık sektöründe ise tüketici kredilerinin - özellikle teminatında herhangi bir varlık bulunmayan ihtiyaç kredileri ve kredi kartlarının - bir kriz anında Sermaye Yeterlilik Oranı'na ilk etki edecek unsurlar olduğu muhtelif çalışmalarda görülmektedir.

Bu çalışma, Türkiye'de tüketici kredilerinde finansal istikrarsızlığa yol açabilecek artış hızının dengelenmesi amacıyla Haziran 2011 tarihinde, karşılık oranlarının arttırılması ve Aralık 2013 tarihinde tüketici kredi vadesinin kısaltılması şeklinde kurgulanan finansal düzenlemelerin etkinliğini sınamaya yönelik olarak hazırlanmıştır. Bu çalışmadan önce Türkiye özelinde makro intiyati tedbirlerin etkinliğini araştıran bir çalışmaya rastlanılmamış olup, bu bağlamda çalışmada gerçekleştirilen analiz ile uygulanan makro ihtiyati politikaların etkinliği Türkiye'de ilk kez sınanmıştır. Çalışma iki ana bölümden oluşmaktadır. Illk bölümde, makro intiyati tedbirlere ilişkin detaylı bir teorik çerçeveye yer verilmiştir. İkinci bölümde ise, tüketici kredilerinde karşııık oranlarının arttırılması ve vade kısıtlaması şeklinde uygulanan tedbirlerin etkinliği En Küçük Kareler (EKK) ve Genelleştirilmiş Momentler Yöntemi (GMY) tahmin edicileri kullanılarak sınanmış ve elde edilen bulgular açıklanmıştır.

\section{TEORIK ÇERÇEVE}

\subsection{Sistemik Risk ve Makro İhtiyati Politikaların Amacı}

IMF, FSB ve BIS tarafından G20 için hazırlanan bir çalışmada (2010) sistemik riskin, finansal sistemin tümünde ya da bir bölümünde ortaya çıkan 
aksaklıkların, reel ekonomi üzerinde ciddi sonuçlar yaratacak ölçüde finansal hizmetleri kesintiye uğratması riski olarak tanımlandığı görülmektedir. Burada finansal hizmetler kredi aracılığını, risk yönetimini ve ödeme hizmetlerini içermektedir. Zachary vd. (2015) sistemik riskin, sistemin kendi karakterinden gelen nedenlerle finansal sistemin başarısızlıklara duyarlı hale gelme riski olduğunu belirtmektedirler. Uluslararası Ödemeler Bankası (BIS) (2010)'a göre sistemik risk tanımının net olmaması, zamana, ekonomiye ve özel şartlara bağlı olmasının yanında finansal sistemin davranışları, ekonomi ile etkileşimi ve politika müdahalelerine duyarlıı̆̆ı konusunda elde yeterince bilgi bulunmamasından kaynaklanmaktadır. Maliyeti çok yüksek olan bu risk, finansal kurumlara yönelik etkin makro ihtiyati düzenleme araçlarının tasarlanmasını ve yürürlüğe konulmasını gerektirmektedir. Clement (2010)'a göre "makro ihtiyati" teriminin ilk kullanımı 1979 yılına dayanmaktadır. Makro ihtiyati politikaya ilk genel referanslar 1986 yılında BIS'in bu politikayı finansal sistemin tümünün ve ödemeler sisteminin güvenliği ve sağlığı açısından tartışmaya başlaması ile ortaya çıkmıştır. Galati ve Moessner (2011), düzenleme ve denetlemeye makro ihtiyati yaklaşımın 2000 'li yılların başında gündeme geldiğini ve 2008 finansal krizinden sonra ise bu terimin çok daha fazla kullanılmaya başlandığını ifade etmişlerdir.

2007-2008 krizinden önceki son yirmi yılda para politikasında literatür politika araçları konusunda önemli değişimler görmüş ve son gelinen noktada para politikasının fiyat istikrarını sağlamak üzere yapılandırılması gerektiği görüşü öne çıkmış bulunmaktadır. Makro intiyati politika konusunda ise literatür böyle bir konsensustan uzak durumdadır. Genel olarak bakıldığında makro ihtiyati politikanın finansal istikrarı amaçladığı kabul edilmektedir. Ancak finansal istikrarın ortak paylaşılan bir tanımı da halen yapılamamıştır. Bu konudaki görüşler geniş çerçevede ikiye ayrılabilir. Birincisi finansal istikrarı finans sisteminin dış şoklara dayanıkııı̆ı olarak tanımlamaktadır. Bu görüşe Allen ve Wood (2006) ve Padoa-Schioppa, (2003)'ün çalışmaları örnek olarak verilebilir. İkincisi finansal sıkıntıların endojen yapısına vurgu yapmakta ve finansal istikrarı finansal sistemin içinden gelen şoklara dayanıklılık olarak tanımlamaktadır. Bu konuda Schinasi (2004)'ün çalışmaları örnek olarak verilebilir.

Makro intiyati politikaların spesifik amaçları konusunda genel görüş, kullanılan dilde ve vurgulanan noktalarda farklılıklar olsa da sistemik krizlerin yarattığı riskleri ve maliyetini azaltmak olduğu belirtilmektedir. Ingiltere Merkez Bankası (BoE) (2009), genel anlamda makro ihtiyati politikaların, son küresel krizde kendini gösteren kredi aracılığı ve likiditedeki büyüme şeklindeki çöküş döngülerinden kaçınmaya çalışarak, finansal aracılık hizmetlerinin (ödeme sistemi, kredi aracılığı, risklere karşı sigorta gibi) ekonomiye istikrarlı bir şekilde katkıda bulunmasını hedeflemesi gerektiğini vurgulamaktadır.

\subsection{Makro ve Mikro İhtiyati Kurallar Açısından Döngü Yönlülük}

Crocket 2000 yilında, Borio 2003 yılında iki perspektifin doğasına ilişkin yapıyı ortaya koymuşlardır. Politikalar arasındaki farka bakılarak makro politikaların doğasını anlamak iyi bir başlangıç olabilir. Bu yaklaşımlara göre; Ortalama hedef ve nihai hedef makro intiyati tedbirlerde sırasıyla sisteme yaygın sorunların çözülmesi ve finansal istikrarsızlığa bağlı ekonomik maliyetlerden kaçınma olarak tanımlanırken aynı hedefler mikro ihtiyati tedbirler kapsamında bir kurumun sıkıntılarının azaltılması ve tüketicinin, yatırımcının ve mevduat sahibinin korunması olmaktadır. Riskin karakteri, makro ihtiyati tedbirlerde endojen ve kollektif davranışa bağı iken mikro ihtiyati tedbirler söz konusu olduğunda riskin karakteri exojen ve tek bir kurumun davranışına bağlı olmaktadır. Makro intiyati kontrollerin yapılandırıması anlamında makro intiyati perspektif sisteme yaygın riskleri dikkate almakta iken mikro ihtiyati yaklaşım ise her bir kurumun yarattığı risklere odaklanmaktadır.

Caruana, (2010) makro ihtiyati politikaların amacının; tüm finansal kurumların birbirlerine bağımlılıklarına ve genel riskliliklerine, döngü yönlü (procyclical) finansal sisteme açıkça hitap ederek sistemik risklerin azaltılması olarak tanımlamıştır. BIS (2008)'e göre döngü yönlülük terimi, genel olarak etki arttırıcı mekanizmaları ifade eder. Bu sayede iş döngülerini güçlendirir (pozitif geri bildirim) ve sonucunda muhtemelen finansal istikrarsızlığa yol açar yada finansal istikrarsızlığın etkisini arttırır. Bu geri bildirim mekanizması özellikle ekonominin yönünün aşağıya doğru olduğu dönemlerde yıkıcıdır ve daha görünür hale gelir.

Bunun karşılığında kurum kredilerini kesebilir ya da elindeki varlıkları satabilir. Bu yöntem ekonomik aktiviteyi azaltır ve finansal gücün daha da zayıflaması riskini doğurur. Özellikle kurumun sorumluluklarını yerine getirememe ve iflas riski piyasa oyuncularının 
savunmacı bir tutum izlemesine yol açar. Ordonez (2009)'a göre, kötü yönetilen bir bankadan daha fazla döngü yönlü hiçbir şey olamaz. Buradaki temel sorun, piyasanın olumlu olduğu dönemde bankaların yeterince emniyet stoku biriktirememiş olması nedeniyle zor dönemde oluşan bir daralmanın daha da yıkıcı hale gelmesine sebep olunmasıdır. Sonuç olarak sistem şokun etkisini azaltmak yerine arttıran bir işlev görür.

Finansal sistemin döngü yönlülüğü iki temele dayandırılabilir; Bunlardan birincisi, riskin hesaplanmasındaki kısıtlardır. Genel olarak ekonomiye birbirini takip eden iyimserlik ve kötümserlik havası hâkim olabilir. Tansiyon arttığında risk ölçümlerinde sıklıkla yükseliş̧ olur ancak bu yükseliş̧ oldukça düşük seyredebilir. İkinci temel, teşviklerin çarpıtılmasında yatmaktadır. Riskin hesaplanmasında bir problem olmasa bile çarpıtılmış teşvikler kendi başına bile döngü yönlülüğü destekler. Temel döngü yönlülük kaynaklarının dışında, mevcut politika çerçevesi unsurları da duruma katkı yapan faktörler olabilirler. Yürürlükteki ihtiyati kurallar ve muhasebe standartları finansal sistemin döngü yönlülüğüne katkı yapabilir yada etkisini azaltabilir. Örneğin intiyati kurallardaki minimum sermaye gereksinimi ve likidite gereksinimi gibi risk önlemleri kredi ve iş döngülerindeki pozitif geri bildirim mekanizmalarını güçlendirebilir ve daralma döneminde düzenleme kısıtlamaları ilk önce sıkıntı yaratmaya başlayan unsur olabilir. Tunay (2014), yapılan düzenlemelerin döngü yönlülüğü arttırıcı etkileri olduğuna ilişkin literatürdeki eleştirileri açıklamıştır.

Bu kapsamda Basel II ve bir takım uluslararası muhasebe düzenlemelerinin döngüsel dalgalanmaları artırıcı etkisinden bahsedilmektedir. Politika tedbirleri ile bu döngü yönlülüğü ortadan kaldırmaya çalışmak gerçekçi gözükmemekle birlikte bütün olarak finansal sistem için önemli sorun yaratan risklerin azaltılması mantıklı olacaktır. Burada anahtar mekanizma, büyüme dönemlerinde sistemde güvenli tamponlar (sermaye tamponu, vb.) oluşturmak ve sıkıntılı dönemlerde bunun kontrollü kullanımını sağlamaktır. Tamponlar, amacına uygun olarak kullanıldığında baş gösteren sıkıntılara karşı sistemin esnekliğini arttırabilir. Tamponların oluşturulması aynı zamanda büyüme dönemlerinde aşııı risk almayı ve bilançoların aşıı büyümesini sınırlayabilir. Bu da sonuç olarak sistemik sıkıntı döneminde kamu desteği beklentisi ile oluşan teşvikle risk alma düşüncesinin etkisini azaltabilir (Ahlaki riziko). Döngü yönlülükle mücadele, makro ihtiyat temeline dayanan düzenleme denetleme çerçevesinin bir parçası olmaktadır (BIS, 2008).

\subsection{Döngü Yönlülüğün Bankalara ve Banka Bilançolarına Etkisi}

Kredinin kullanılabilir durumda olması ve iş döngülerinde kredilendirmede değişim, oldukça önemli bir çalışma konusudur. Toplam kredilerde döngüye bağlı değişim beklenilen bir gelişmedir. Ekonominin zayıf olduğu dönemlerle kıyaslandığın$d a$, ekonominin güçlü dönemlerinde net bugünkü değeri pozitif olan ve fonlama talep eden proje sayısı daha fazladır. Bu nedenle ekonominin yukarı yönlü sıçrama yaptığı dönemlerde toplam kredi stokunda artış, aşağı doğru bir ivmelenme olduğunda stokta düşüş beklenilir. Adrian ve Shin (2013) bu yönden bakıldığında, finansal sistemde döngü yönlülük konusunun karmaşık bir konu olduğunu belirtmektedir. Gertler (1988), Fisher ve Keynes'le başlayan makroekonomideki alternatif geleneğin, iş döngülerindeki dalgalanmaların artmasında kredi-piyasa şartlarına etkin rol verdiğini belirtmektedir.

Adrian ve Shin (2010)'un çalışmasına göre, Banka bilançolarının sürekli olarak piyasa fiyatı ile değerlemeye tabi tutulduğu bir finansal sistemde, varlık fiyatlarındaki değişimler hemen bilançoya yansımakta ve finansal sistemi oluşturan tüm parçaların net değeri üzerinde etkili olmaktadır. Özellikle finansal aracıların öz sermayeleri bilançolar yüksek kaldıraçlı olduğunda bu değişimlere daha fazla duyarlı hale gelmektedirler. Finansal aracılar, bilançolarını aktif biçimde ayarlamaktadırlar. Yani büyüme dönemlerinde yüksek kaldıraç kullanılmakta, daralma dönemlerinde kaldıraç kullanımı düşürülmektedir. Döngü yönlü olan kaldıraç, fiyatlarda ve ölçülen risklerde değişimlere karşılık veren finansal aracıların bilançolarını aktif yönetimi sonucunda ortaya çıkmaktadır. Finansal aracılar bakımından risk modelleri ve sermaye, riskli değerlerin bilançoda değişikliğe gidilerek aktif yönetilmesini gerekli kılmaktadır. Özkaynakların piyasa değerinde bir artış ve hesaplanan risklerde bir azalma meydana gelmektedir. Banka bilançosunda bu değişikliklerden sonra kullanılmayan fazla kapasite meydana çıkmaktadır. Bu fazla bilanço kapasitesi daha fazla borç alınarak daha fazla kredilendirme işleminde kullanılmaktadır.

\subsection{Döngü Karşıtı Finansal Düzenlemeler}

Finansal piyasaların kökeninde bulunan istikrarsızlık Keynes (1936)'in değerli görüşlerinden biri olmuştur. Bu görüş Minsky (1982) tarafından daha 
fazla vurgulanmıştır. Temel neden, finansın kesin olarak tahmin edilmesi mümkün olmayan gelecekteki sonuçlarla ilgili olmasıdır. Dolayısı ile finansal piyasa kararlarını gerçek bilgiden daha fazla düşünce ve beklentiler yönlendirmektedir. Stiglitz (2001)'e göre bu durum ayrıca finansal piyasaları karakterize eden asimetrik bilgi ile birleşmektedir.

Griffith-Jones vd. (2009) finansal aracıların, büyük oranda diğer piyasa katılımcılarının davranışlarına güvendiğini ve daha fazla diğerlerine bağımlı hale geldiğini öne sürmüştür. Bu durum kendisini bulaşma ve sürü davranışı kavramlarında göstermektedir. Olumsuz ya da olumlu düşüncelerin ve beklentilerin bulaşıcı olması Ocampo (2003)'e göre birbirini takip eden coşku ve panik evrelerinin temel nedenidir. Griffith-Jones (1998) ve Persaud (2003), bu sürü davranışı ve dalgalanmanın, piyasa riskine duyarlı risk yönetimi teknikleri ve çok kısa dönem aralıkları ile değerlendirilip, kısa dönemli kâr amaçlayan yatırım yöneticileri tarafından daha da güçlendiğini belirtmektedirler. Borio vd. (2001), finansal istikrarsızlıkların temelinde finansal sistemin döngü yönlü olması olgusunun varolduğunu öne sürmektedir. Finans, özellikle bankacılık aktiviteleri doğası gereği iş akışlarının etkisini arttırmak anlamında döngü yönlüdür. Büyüme dönemlerinde, kredi genişlemesi ekonomik büyümenin ilerisinde gelişme kaydeder. Ekonominin daraldığı dönemlerde ise azalan şirket kârları, hanehalkı gelir ve servetinde daralma gibi nedenlerle borç alanların kredi değerliliğinde azalma meydana gelir ve kötüleşen teminat değerleri, yükselen risk algısı ve borç verme standartlarında sıkılaşmadan dolayı kredilendirme daha zor hale gelir. Bu durum ekonomik beklentilerin kötüleşmesine yol açar.

Huacong (2011), döngü karşıtı finansal düzenlemelerin temelde iki amacı bulunduğunu bildirmektedir. İlki, gelecekte olası bir kötüye gidişte finansal sistemin esnekliğini arttırmak, Diğeri ise, döngülerde rüzgara karşı durmak, aşırı kredi genişlemesini durdurmak, aşııı risk almayı engellemek ve işler artarken dengesizliklerin birikmesine engel olmaktır. Ancak politika oluşturulurken bunların ağırlıklarının ne olacağı konusunda bir ortak görüş oluşmamıştır. Döngü karşıtı finansal düzenlemelerin kurala bağı mı olacağı yoksa ihtiyari yani takdire bağlı mı yapılandırılacağı konusunda tartışmalar sürmektedir. İki yaklaşımın da kendi içinde güçlü ve zayıf yönleri bulunmaktadır. Kurala bağlı ya da ihtiyari olarak yapılandırılsa da, döngü karşıtı rejim gösterge setinin seçilmesi ve sistemik riskin tespiti açısından sistemin sürekli izlenmesini ve doğru politikalarla risklerin kontrol altına alınmasını gerektirmektedir. Drehmann, vd. (2010)'a göre potansiyel göstergeler olarak GSMH, kredi gelişimi, kredinin gayri safi milli hasılaya oranı ve borç verme standartları gibi krediye ilişkin yaklaşımlar, varlık fiyatlarındaki artış, kredi ve likidite spredleri, finansal kurumlar, şirketler ve hane halkının kaldıraç kullanımı, likidite ve döviz pozisyon uyuşmazlığı gibi bankacılık performansı ya da sağlığına ilişkin göstergeler kullanılabilir.

IMF (2009), 2008'deki küresel finans krizinin politika yapıcıların harekete geçmekte isteksiz ya da yavaş davrandıklarını gösterdiğini ve bu durumun kurala bağlı çerçevenin yararlı olacağını işaret ettiğini belirtmektedir. Bu nedenle çerçeveye mümkün olduğu ölçüde döngü içinde harekete geçecek otomatik düzenleyicilerin yerleştirilmesini önermektedir. Bugüne kadar elde edilen tecrübelerin yetersiz olması nedeniyle döngü karşıtı önlemlerin etkisini tümüyle değerlendirmek mümkün gözükmemektedir. Bununla birlikte, ekonominin yukarı doğru gittiği dönemlerde kredi artışını azaltmak konusunda sınırlı, buna karşın ekonomide aşağı yönlü risklere karşı finansal sistemin esnekliğinin arttırılmasında daha fazla başarı elde edilebilmektedir.

Ayrıca, önlemlerin başarısı yukarıda ifade edildiği gibi genel ekonomik durumla da yakından ilgilidir. Gevşek para politikası izlenmesi durumunda kredi genişlemesinin engellenmesi için ihtiyati kurallar yeterli olmayabilir. Böyle bir ekonomik durumda belli sektörleri hedef alan düzenlemeler getirilebilmektedir. Huacong (2011) genel çerçevede, birbirleri ile ilintili farklııklar göz ardı edilmeden döngü karşıtı düzenlemelerin, karşılık ayırma önlemleri, sermayeye ilişkin önlemler ve belirli sektörlere/segmentlere yönelik önlemler olarak belirlenebildiğini kaydetmiştir.

Fernández de Lis ve Garcia-Herrero (2010) çalışmalarında diğer döngü karşıtı önlemler olarak Basel III, İleriye Dönük Karşılık Ayırma ve Beklenen Zarar Karşıı̆ı̆ gibi konuları ortaya koymuşlardır. Türkiye gibi gelişmekte olan ülkelerde ihtiyati tedbirler belirlenirken genel trendlerin gelişmiş ülkelerden farklı olduğu göz ardı edilememeli ve bu döngü karşıtı önlemler ayrıca incelenmelidir.

\subsection{Sektörel Önlemler}

Spesifik segment ve sektörleri hedef alan döngü karşıtı önlemler aralarında Türkiye'nin de bulunduğu birçok ülkede kullanılmaktadır. Bu ülkelerin birçoğu 
özellikle Asya ülkeleri gayrimenkul döngüleri ile uğraşmaktadırlar. Burada alınan önlemlere mortgage kredilerinde kredi değer oranını, bireysel kredilerde borç gelir oranını değiştirmek ve döngünün aşamasına göre bazı risk grupları için risk ağırlıklarının ve karşılık oranlarının değiştirilmesi örnek olarak verilebilir. Bu önlemlerin bazıları kredi miktarını direk olarak etkilerken diğerleri ise risk ağırlıklarını arttırma ve karşıık ayırma gibi yöntemlerle kredi arzını dolaylı olarak etkilerler.

Genel önlemlerin aksine sektöre özel önlemler daha belirgin ve bu sektörlerde ortaya çıkan risklerle mücadelede daha etkin olmaktadırlar. Örneğin kredi-değer oranı tavanı düzenlemesi gayrimenkul döngülerinin yarattığı sorunlara çözüm amacıyla Çin, Hong Kong, Güney Kore gibi birçok ülkede uygulanmaktadır. Kredi-değer oranı düzenlemeleri alınan kredinin miktarının teminatın değerine göre oluşan kaldıracının sınırlanmasına dönük uygulamalardır. Bu sınırlama bir yandan yüksek riskli borçluların izlenerek potansiyel geri ödememe riskini azaltırken diğer yandan kredi geri dönüşü sekteye uğradığında oluşacak potansiyel zararı düşürmeye yardımcı olur.

\section{EKONOMETRIK ANALIZ}

\subsection{Daha Önce Yapılmış Ampirik Çalışmalar}

Lim, vd. (2011) sıklıkla kullanılan makro ihtiyati politika araçlarının döngü yönlülüğü azaltmada etkin olduğunu, ne kadar etkin olduğunun finansal sektörde karşılaşılan şok türüne de bağlı olduğunu ortaya koymuşlardır. Çalışmalarında elde ettikleri bulgulara kapsamında hangi makro ihtiyati politikaların hangi koşullar altında etkin olup olmadığını da tanımlamışlardır. Alberola, vd. (2011) İspanya'da döngü karşıtı uygulanan kredi-değer oranı düzenlemesinin ev fiyatları ve kredi büyümesindeki aşırı artışı sakinleştirdiğini ortaya koymuşlardır.

Claessens, vd. (2013) bankacılık sistemindeki kırılganlıklara odaklanmış farklı makro ihtiyati politikaların etkinliğini sınadıkları çalışmasında, borç-gelir oranı, kredi-değer oranı sınırlamalarının yanı sıra kredi büyüme sınırlaması ve yabancı para borçlar üzerine kısıtlamalar gibi düzenlemelerin aşırı büyümeyi ve balon etkileri engellediğini göstermişlerdir. Ayrıca makro ihtiyati politikaların asimetrik etkilerin varlığı nedeniyle piyasa başarısızlıklarını engellemede daha etkin olduğunu ortaya koymuşlardır. Kuttner ve Shim (2013), gelişmiş ve gelişmekte olan ülkeler için makro-ihtiyati araçların konut fiyatları ve kredileri üzerindeki etkisini sabit etki panel regresyon ile test etmişlerdir. Analiz sonucunda en başarılı aracın borç-gelir limiti olduğu daha sonra da borç-gelir limiti kadar olmasa da kredi-değer limitinin de etkili olduğu sonucuna varılmıştır.

Lee, vd. (2015) Asya ülkeleri için gerçekleştirdikleri analizlerde makro ihtiyati politikaların finansal istikrarı desteklediğini, makro ihtiyati politika türlerinin her bir makroekonomik risk için farklı sonuçları olduğunu, farklı türdeki makroekonomik risklerin azaltılması ve etkin sonuçların alınması için farklı makro ihtiyati politikaların uygulanması gerektiğini göstermişlerdir.

\subsection{Analiz Yöntemi}

Kurulan modeller EKK (En Küçük Kareler) ve GMY (Genelleştirilmiş Momentler Yöntemi) tahmin edicileri ile tahmin edilmiştir. EKK tahmin edicisinin yanı sıra modellerin GMY ile de tahmin edilmesinin en temel sebebi GMY tahmin edicisinin moment koşulları dışında ekstra herhangi bir bilgi kullanmadığı için tutarlı, asimtotik olarak normal dağılım gösteren, etkin (efficient) bir tahmin edici olmasıdır. Bu özellikleri ile GMY tahmin edicisi standart regresyon varsayımlarına karşı oldukça güçlü (robust) bir tahmin yöntemi sunmaktadır. Çünkü Hansen (1982) moment koşullarının zayıf varsayımlar altında bile tutarlı parametre tahminlerinde kullanılabileceğini göstermiştir. Örneğin EKK tahmin edicisinin temel varsayımlarından biri bağımsız değişkenler ile hata terimleri arasında korelasyon (otokorelasyon) bulunmadığı varsayımıdır. Bu varsayımın geçerli olmaması durumunda EKK tahmin edicisi tutarlı olmamaktadır.

Ancak otokorelasyonun varlığı altında bile GMY tahmin edicisi tutarlı parametreler sağlamaktadır. GMY yönteminde araç değişkenleri içeren moment koşulları parametre vektörünün boyutundan büyük ise bu durumda modelin aşırı belirlenmiş (overidentified) olması söz konusudur. Aşırı belirlenme kısıtlarının (over-identifying restrictions) geçerli olması moment koşullarının yeterli olup olmaması açısından önemlidir. Bu nedenle GMY yönteminde modelin geçerliliğini - dolayısıyla aşırı belirlenme kısıtlarının geçerliliğini - test etmek için sadece Sargan J testi "aşırı belirlenme kısıtları geçerlidir" boş hipotezi altında uygulanmaktadır. Modeli daha düz hale getirmek ve daha anlamlı sonuçlar elde etmek için tahminlerde kullanılan tüketici kredisi ve SÜE değişkenlerinin logaritması alınarak model LOG-LOG haline çevrilmiş ve bu şekilde tahmin edilmiştir. 
Zaman serileri tesadüfi (random) değişkenler ile çalışan stokastik bir süreci barındırır. Bu nedenle bir zaman serisinin deterministik ve stokastik özellikleri vardır. Deterministik özellik sabit terim, katsayılar, trend ve mevsimselliği işaret etmekte iken, stokastik özellikte değişkenin durağan olup olmadığı önem kazanmaktadır. Durağanlık, stokastik (tesadüfi) bir serinin uzun dönem ortalamasının, varyansının ve covaryansının sabit olmasıdır. Tahmin analizine konu bir seri durağan değilse, bu serinin katsayısı / tahmin sonuçları sadece ele alınan dönem için geçerli olacak olup, tahmin sonuçları ile ilgili evrensel nitelikli değerlendirmeler yapılması mümkün olmayacaktır.
Bu bağlamda durağan olamayan serilerle yapılacak tahminlerde "sahte regresyon (sprious regression)" sorunu ortaya çıkabilecektir. Bir seri, birim kök içermesi halinde durağan olmayacaktır. Birbirinden bağımsız durağan olmayan serilerin modelde kullanılması halinde t-istatistikleri anlamlı ve $R^{2}$ yüksek çıkabilir. İşte bu durumda durağan olmayan serilerle yapılacak tahminlerde regresyon tahmini sahte/ geçersiz olabilecektir. Birim kök testlerinde DickeyFuller türü testler yoğun olarak kullanılmaktadır.

Makro intiyati tedbirlerin etkinliğini ortaya koymaya çalıştığımız uygulamalı analizde kurulan model (1) de gösterilmektedir:

$$
\log (\mathrm{TKR})_{\mathrm{t}}=\alpha_{0}+\alpha_{1} \mathrm{DGK}_{\mathrm{t}}+\alpha_{2} \mathrm{DVS}_{\mathrm{t}}+\alpha_{3} \Delta \log (\mathrm{SUE})_{\mathrm{t}}+\alpha_{4} \mathrm{TREND}_{\mathrm{t}}+\epsilon_{\mathrm{t}}
$$

$$
Z_{t}=\left\{\log (T K R)_{t^{\prime}} \log (T K R)_{t-1} \Delta \log (S U E)_{t^{\prime}} \Delta \log (S U E)_{t-1^{\prime}} D G K, D V S\right\}
$$

Söz konusu modelde DGK ve DVS sırasıyla; BDDK tarafından yapılan genel karşılıklar ve vade sınırlaması düzenlemelerini gösteren kukla değişkenleri, TKR; konut ve taşıt finansmanı dışında kalan tüketici kredilerini, SUE; sanayi üretim endeksini ve TREND değişkeni de bağlı değişkenin bariz artış eğilimi göstermesi nedeniyle oluşabilecek tahmin hatalarını kontrol etmek için modele eklenen eğilim parametresini göstermektedir. (2) no.lu eşitlikte belirtilen $Z_{t}$ GMY tahmininde kullanılan araç değişkenleri vektörünü göstermektedir.

(1) no.lu modelde sanayi üretim endeksi ekonomik gelişimi kontrol eden koşul değişken olarak modele eklenmiş olup, bu değişkenin 1. derece farkının modele eklenmesinin sebebi yapılan durağanlık testleri sonucu SUE verisinde seviye değerinde bir birim kök tespit edilmesidir. Yapılan literatür araştırmasında, makro ihtiyati önlemlerin etkinliğini yukarıdaki modeller yardımıyla sınamak için yapılan herhangi bir uygulamalı analiz ile karşılaşılmamıştır.

\subsection{Veri Seti}

Bu çalışma 2005 Ocak - 2016 Temmuz dönemini kapsayan aylık verilerle yapılmış olup, veri seti 139 zaman serisi verisini içermektedir. 2001 krizi sonrasında Türkiye'de bankacılık sektörüne ilişkin reform niteliğinde önemli bir dizi düzenleme yapılmıştır. Söz konusu düzenlemelerin sonuçlarının görülmeye başladığı yıl olan 2005 yılı veri setinin başlangıç seçilmiş olup, mevcut olan en son veri tarihi olan 2016
Temmuz ayına kadar olan dönem inceleme konusu olmuştur. Söz konusu dönemin en önemli iktisadi gelişmesi kuşkusuz mortgage krizi olarak bilinen 2008 küresel finans krizidir. Söz konusu kriz sonrası dünya ekonomisinde genişleyici para politikaları uygulanmaya başlanmış olup, bu dönem piyasalarda likidite bolluğunun yaşandığı bir dönem olmuştur. Söz konusu politikalar aynı zamanda gelişmekte olan piyasalarda daha volatil bir durum ortaya çıkarmış ve Bankacılık piyasasına dönük makro ihtiyati politika uygulamaları/çalışmaları bu dönemde yoğunluk kazanmıştır.

Çalışmada; BDDK tarafından yayımlanan bankaların ayırdığı genel karşılıklarda artışa gidilmesi ve tüketici kredilerinde azami vadenin 36 aya çekilmesi düzenlemelerinin, Bankacılık sektörünün kullandırdığı tüketici kredilerine (konut kredisi hariç) etkisinin sınanması için, belirtilen düzenlemeler "kukla değişken" olarak modele eklenmiştir. Genel Karşılıklar düzenlemesi Temmuz 2011; tüketici kredilerinde vadeyi kısaltan vade sınırlaması düzenlemesi Ocak 2014 tarihlerinden sonra başlamış olup, kukla değişkenlere ilişkin veri seti belirlenirken söz konusu tarihler dikkate alınmıştır.

Kukla değişkenlerin tüketici kredisine etkisini gösterebilmek için kurulan regresyon modeline, modeli daha doğru şekilde tahmin edebilmek için sanayi üretim endeksindeki değişim (DSÜE) ve TREND serileri kontrol değişkeni olarak modele eklenmiştir. Sanayi Üretim Endeksi ekonomik büyümenin öncü 
göstergelerindendir. Söz konusu endekste oluşan artışlar ilerleyen dönemde ekonomide büyüme yaşanacağını, azalışlar ise ekonomik bir durgunluğu işaret etmektedir. Hanehalklarının tüketici kredilerine olan talebinde ülkenin ekonomik büyüme ve refahı önemli bir rol oynamaktadır.

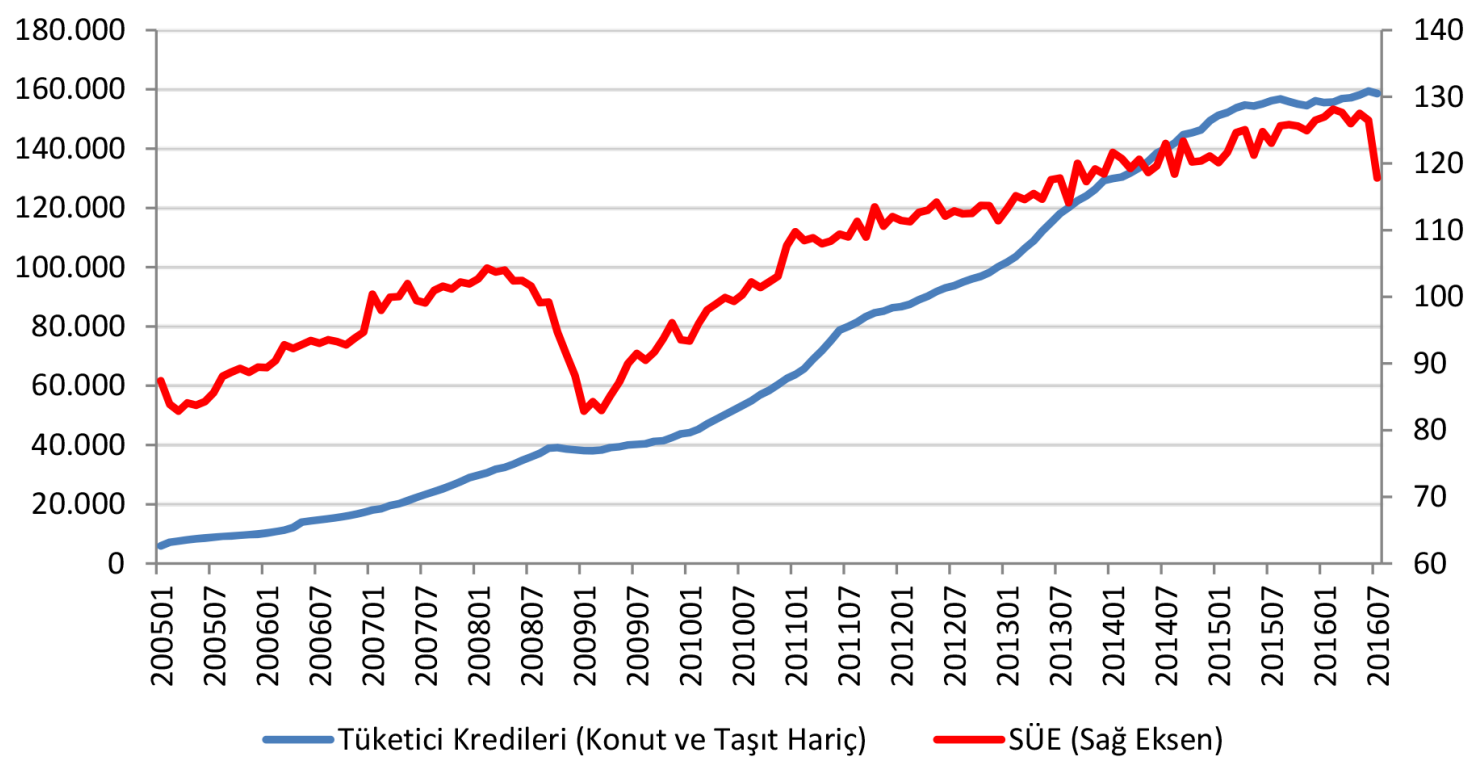

Şekil 1: Tüketici Kredileri ve Sanayi Üretim Endeksinin Gelişimi

Gelecek dönemde reel gelirlerinin artacağını düşünen hanehalkları, gelecek dönem için planladığı harcamalarını tüketici kredileri ile finanse ederek bugünkü tüketim ve refahını artırma eğilimi göstermektedir. Bu nedenle SÜE verisi, tüketici kredileri üzerinde hanehalklarının gelirlerinde üretim (büyüme) kaynaklı oluşacak bir dolaylı artışın etkisini kontrol etmek için modele kontrol değişkeni olarak eklenmiştir. Trend değişkeninin kontrol değişkeni olarak eklenmesinin sebebi ise, tüketici kredilerinde 2005-2016 döneminde bariz bir artış eğilimin var olduğunun görülmesidir. Söz konusu trend etkisinin modele dahil olmaması halinde standart hatalar yükselecek, tahmin katsayıları hatalı hesaplanabilecek, modelin tutarlıı̆ı azalabilecektir. Bu nedenle zaman içinde oluşan artış eğilimini kontrol etmek için modele trend değişkeni eklenmiştir.

Modelde yer alan Sanayi Üretim Endeksi (SÜE) verisi Türkiye İstatistik Kurumu (TÜIK) web sitesinden, Tüketici Kredisi (TKR) verileri ise BDDK'dan temin edilmiş olup, veri seti "aylık" verilerden oluşmaktadır. Kullandırılan tüketici kredilerinin tamamının amacına uygun şekilde bireysel intiyaçların finansmanı amacıyla kullandırıldığı varsayılmıştır.

\subsection{Bulgular}

Yukarıda (1) no.lu denklemde yer alan değişkenlerden Tüketici Kredileri (TKR) ve Sanayi Üretim Endeksi
(SÜE) değişkenleri haricinde yer alan değişkenlerin kukla değişken ve trend değişkeni olması sebebiyle, sahte regresyon sorunu TKR ve SÜE değişkenlerinin durağanlık testlerinin yapılması ile araştırılacaktır. Tüketici Kredileri (TKR) ve Sanayi Üretim Endeksi (SÜE) değişkenlerinin durağan olup olmadığı Augmented Dickey Fuller (ADF) ve Philips Perron (PP) birim kök testleri ile sınanmıştır.

Tablo 1: Birim Kök Testleri

\begin{tabular}{|l|c|c|c|c|}
\hline \multirow{2}{*}{ Değişken } & \multicolumn{2}{|c|}{ ADF } & \multicolumn{2}{c|}{ PP } \\
\cline { 2 - 5 } & Seviye & Birinci Fark & Seviye & Birinci Fark \\
\hline Log(TKR) & $-3.78^{*}$ & - & $-4.95^{*}$ & - \\
\hline Log(SÜE) & -2.01 & $-6.90^{*}$ & -1.08 & $-12.34^{*}$ \\
\hline
\end{tabular}

*\%1 anlamlılık düzeyinde serilerin durağan olduğunu göstermektedir.

Birim kök testleri sonucu Tüketici Kredisi (TKR) serisinin seviye değerinde durağan, I(0), olduğu, buna karşın Sanayi Üretim Endeksi (SÜE) serisinin birinci farkı alındığında durağan, I(1), hale geldiği anlaşılmıştır. SÜE serisinin seviye değerinin durağan olmadığı görüldüğünden sahte regresyon sorununun ortaya çıkmaması için söz konusu değişken birinci farkı alınarak durağan hale getirilmiş ve modele SÜE değişkeninin birinci farkı (logaritmik farkı alındığından bu değişken aynı zamanda SÜE'deki 
gelişimi göstermektedir.) eklenerek model tahmini gerçekleştirilmiştir.

EKK ve GMY tahmin edicisi ile yapılan tahminlere ilişkin tahmin sonuçları Tablo 3'te gösterilmektedir. EKK tahmininde otokorelasyon sorunu ile karşılaşılmış olup, bu sorunu ortadan kaldırmak için Newey-West değişen varyans ve otokorelasyon tutarlı standart hatalar ve kovaryansları içeren Newey-West güçlü (robust) tahmin edicisi kullanılmıştır. Newey-West tahmin edicisi Newey ve West (1987) tarafından, zaman serisi regresyonlarında otokorelasyon (seri korelasyon) ve değişen varyans sorunlarının üstesinden gelinmesi için geliştirilmiştir. Bununla birlikte GMY tahmininde de daha güçlü (robust) sonuçlara ulaşmak ve olası otokorelasyon sorununa karşı tutarlı standart hatalar ve kovaryanslar elde etmek için Newey-West prosedürü uygulanmıştır.

Tahmin sonuçlarına göre modelin açıklayıcılık gücünü gösteren düzeltilmiş $\mathrm{R}^{2}$ değerleri modelin açıklayıcılık gücünün \%95 üzerinde olduğu göstermektedir. Yüksek $\mathrm{R}^{2}$ ile birlikte modeldeki değişkenlerin t-istatistiklerinin anlamlı olmasının, modelde çoklu doğrusallık (Multicollinearity) sorununun bulunmadığını göstermesi açısından anlamlıdır. F istatistikleri tahmin edilen modellerin \%1 anlamlılık düzeyinde genel olarak anlamlı modeller olduğunu göstermektedir. Sargan testi p-değeri, GMY tahmininde kullanılan araç değişken vektörlerinin geçerli olduğunu göstermektedir.

Tablo 3: Tahmin Sonuçları

\begin{tabular}{|l|c|c|}
\hline Bağlı Değişken: Log(TKR) & EKK & GMY \\
\hline \multirow{2}{*}{ Sabit } & $9,121^{*}$ & $9,015^{*}$ \\
& $(114,59)$ & $(149,47)$ \\
& $-0,156^{* *}$ & $-0,257^{*}$ \\
& $(-2,012)$ & $(-2,691)$ \\
DVK & $-0,432^{*}$ & $-0,417^{*}$ \\
& $(-4,672)$ & $(-4,838)$ \\
Dlog(SÜE) & $-0,218$ & 4,908 \\
& $(-0,261)$ & $(1,117)$ \\
@TREND & $0,027^{*}$ & $0,029^{*}$ \\
& $(18,70)$ & $(22,23)$ \\
\hline R $^{2}$ & 0,976 & 0,964 \\
\hline R (Düzeltilmiş) & 0,975 & 0,963 \\
\hline F testi & $1362^{*}$ & - \\
\hline J istatistiği & - & 0,0033 \\
\hline Sargan Test p-değeri & - & 0,874 \\
\hline
\end{tabular}

Parantez () içindeki değerler t-istatistiği değerlerini göstermekte olup, ${ }^{*},{ }^{* *}$ ve ${ }^{* * *}$ ile işaretli parametreler istatistiksel olarak sırasılyla \% 1, \%5 ve $\% 10$ seviyelerinde anlamlıdır.
EKK tahmininde kurulan modeller Newey-West ile tahmin edildiği için tahmin sonuçlarında otokorelasyon ve değişen varyans sorunu bulunmamaktadır. Sanayi üretim endeksindeki gelişim hariç tüm diğer değişkenlerin bütün modellerde \%1 ve \%5 seviyelerinde anlamlı olduğu, buna karşın SÜE'deki gelişimi gösteren DlogSÜE değişkeninin tüketici kredileri üzerinde anlamlı bir etkisinin bulunmadığı, DGK ve DVS kukla değişkenlerinin tüketici kredileri üzerinde negatif anlamlı etkilerinin bulunduğu, tüm modellerde trend değişkeninin pozitif ve anlamlı olduğu yönünde bulgular elde edilmiştir.

Analiz sonuçları bir bütün olarak değerlendirildiğinde; tahmin edilen bütün modellerde BDDK tarafından genel karşılıklarda yapılan artışa ilişkin düzenlemeyi gösteren DGK ve tüketici kredilerinde vade sınırlaması düzenlemesini gösteren DVS kukla değişkenlerinin Tüketici Kredileri üzerinde negatif anlamlı bir etkisinin olduğu görülmüştür.

\section{SONUÇ}

Bu çalışmada, makro ihtiyati tedbirler kapsamında tüketici kredilerinde görülen artış hızının kontrol altına alınmasına amacıyla BDDK'nın 18.06.2011 tarihinde karşılık oranlarında yaptığı değişikliğin etkisi ile yine aynı kapsamda 31.12.2013 tarihinde tüketici kredilerine ilişkin olarak kredi vadesinin en fazla 36 ay ile sınırlandırılması düzenlemesinin etkinliği EKK (En Küçük Kareler) ve GMY tahmin edicileri kullanılarak sınanması hedeflenmiştir.

Kurulan modelde sonuç olarak, BDDK tarafından hayata geçirilen genel karşılıklardaki artış ve tüketici kredilerine vade sınırlaması düzenlemelerinin Tüketici Kredileri üzerinde kısıtlayıcı / baskılayıcı anlamlı bir etkisinin bulunduğu sonucuna varılmıştır. Bu bağlamda, BDDK tarafından makro ihtiyati politika çerçevesinde yapılan döngü karşıtı kısıtlayıcı düzenlemelerin, Türk bankacılık sektöründe tüketici kredileri üzerinde beklenen etkinliği göstermiş olduğu bu çalışma ile ortaya konmuştur.

2008 yılında başlayan küresel krizden sonra sıkça gündeme gelen kavramlardan bir tanesi de döngüsellik kavramı olmaktadır. Döngüsellik ekonomik aktivitenin doğasında bulunmakta ve bankacılık sektörünü yakından ilgilendirmektedir. Bankacılık, genel davranış biçimi ile ekonominin döngüsel etkisini daha da güçlendirmekte ve döngü yönlülük göstermektedir. Bu nedenle, makro ihtiyati düzenlemelerin döngü karşıtı önlemler içermesi gerektiği varsayılmaktadır. Söz konusu düzenlemeler, tüm sektörleri 
kapsayacak şekilde yapılandırılabildiği gibi sadece sistemik riskin oluştuğu görülen sektörlere yönelik olarak da kurgulanabilmektedir. Tüm bu anlatılanlar sonucunda, IMF (2004), Demirgüç-Kunt, vd. (1997), Kaminsky, vd. (1998) ve IMF (2004) çalışmalarında da belirtildiği gibi; aşırı kredi büyümesi, finansal istikrarsızlık ve bankacılık krizi arasında güçlü bir ilişki olduğuna dair güçlü teorik alt yapı dikkate alınarak (aşıı hızlı kredi artışının \% 75 oranında bankacılık krizi ile sonuçlandığı belirtilmiştir.) Türkiye'de bankaların kullandırdığı tüketici kredilerinin artış hızını kontrol etmek amacıyla yürürlüğe konan makro intiyati düzenlemelerin tüketici kredilerinin sağlıklı şekilde gelişimine etki ederek bankacılık sektörünün sürdürülebilir büyümesine katkıda bulunduğu söylenebilecektir.

\section{KAYNAKLAR}

Adrian, T. ve Shin H.S.(2010) "The Changing Nature of Financial Intermediation and the Financial Crisis of 2007-09" Federal Reserve Bank of NewYork Staff Report, (439).

Adrian, T. ve Shin H.S.(2013) “Procyclical Leverage and Value-at-Risk" Federal Reserve Bank of NewYork Staff Report, (338).

Alberola, E., Trucharte, C.ve Vega, L.J. (2011) "Central Bank and Macroprudential Policy: Some Reflections from the Spanish Experience" Bank of Spain Occasional Paper Series. (1105).

Allen, A.W.veWood, G. (2006) “Defining and Achieving Financial Stability" Journal of Financial Stability, 2(2): 152-172.

Bank of England (2009) "The Role of Macroprudential Policy", A Discussion Paper, London

http://www.bankofengland.co.uk/publications/

Documents/other/financialstability/ roleofmacroprudentialpolicy091121.pdf, (01.07.2016)

BIS (2008) “Addressing Financial System Procyclicality: A Possible Framework" Basel http://www. financialstabilityboard.org/publications/r_0904e.pdf, (14.06.2016)

BIS (2010) "Macroprudential Instruments and Frameworks: A Stocktaking of Issues and Experiences" CGFS Papers, (38).

Borio, C. ve Drehmann, M. (2009) "Towards An Operational Framework for Financial Stability: 'Fuzzy' Measurement and Its Consequences, BIS Working Papers, (284).

Borio, C., Furfine, Craig., ve Lowe, P.(2001)“Procyclicality of the Financial System and Financial Stability: Issues and Policy Options" BIS Working Papers, (1). Borio, C. (2003) "Towards A Macroprudential Framework For Financial Supervision and Regulation. BIS Working Paper, (128).

Caruana, J. (2010) "Macroprudential Policy: Working Towards A New Consensus Remarks" Speech at the High Level Meeting On the Emerging Framework for
Financial Regulation and Monetary Policy. http://www. bis.org/speeches/sp100426.pdf, (14.06.2016).

Claessens, S., Ghosh, S. R. ve Mihet, R. (2013) "Macroprudential Policies to Mitigate Financial System Vulnerabilities" Journal of International Money and Finance. 39: 153-85.

Clement, P. (2010) "The Term 'Macroprudential': Origins and Evolution, BIS Quarterly Review, March: 59-65.

Crockett, A. (2000) "Marrying the Micro and Macroprudential Dimensions of Financial Stability", BIS Speeches. http://www.bis.org/speeches/ sp000921.htm (14.06.2016)

Demirgüç-Kunt, A. ve Detragiache, E. (1997). "The Determinants of Banking Crises in Developing and Developed Countries." IMF Staff Papers, (45): 81-109.

Drehmann, M., Claudio, B., Gambacorta, L., Jimenez, G., ve Trucharte C. (2010) "Countercyclical Capital Buffers: Exploring Options" BIS Working Papers, (317).

Drehmann, M., Sorensen, S., ve Striga M. (2008) "The Integrated Impact of Credit and Interest Rate Risk on Banks: An Economic Value and Capital Adequacy Perspective" Bank of England Working Paper, (339).

Fernández de Lis, S. ve Garcia-Herrero, A. (2010). Dynamic Provisioning: Some Lessons from Existing Experiences" Asian Development Bank Institute (ADBI) Working Paper, (128).

Galati, G. ve Moessner, R. (2011) "Macroprudential Policy - A Literature Review" BIS Working Papers, (337).

Gertler,M. (1988) Financial Structure and Aggregate Economic Activity: An Overview. Journal of Money, Credit and Banking. 20: 559-88

Griffith- Jones, S. ve Ocampo, J.A. (2009) “Building on the Counter-Cyclical Consensus: A Policy Agenda", Foundation for European Progressive Studies. https:// www.g24.org/wp-content/uploads/2016/01/ Building-on-the-counter-cyclical-consensus.pdf (14.06.2016). 
Griffith-Jones, S. (1998) Global Capital Flows: Should They be Regulated?, 1st Edition, London, Palgrave Macmillan.

Hansen, L.P. (1982) "Large Sample Properties Of Generalized Method Of Moments Estimators" Econometrica, 50(4): 1029-1054.

Haocong, R. (2011) "Countercyclical Financial Regulation" World Bank Policy Research WorkingPaper, No:5823.

IMF (2004) http://www.imf.org/external/pubs/ft/ weo/2004/01/pdf/chapter4.pdf (01.07.2016)

IMF (2009) http://www.imf.org/external/np/pp/ eng/2009/020409.pdf (14.06.2016)

IMF (2011) http://www.imf.org/external/np/pp/ eng/2011/031411.pdf (01.06.2016)

Kaminsky, G., Saul, L. and Reinhart, C. (1998). "Leading Indicators of Currency Crisis." IMF Staff Papers, 45 (1).

Kuttner, K.N. ve Shim, I. (2013) “Can Non-Interest Rate Policies Stabilise Housing Markets? Evidence From A Panel of 57 Economies" BIS Working Papers (433)

Lee, M., Asuncion, R.C. ve Kim, J. (2015) “Effectiveness of Macroprudential Policies in Developing Asia: An Empirical Analysis " ADB Economics Working Paper Series, (439).

Lim, C., Columba, F., Costa, A., Kongsamut, P., Otani, A., Saiyid, M., Wezel, T. ve Wu, X. (2011) "Macroprudential Policy: What Instruments and How to Use Them? Lessons from Country Experiences" IMF Working Paper Series. 11 (238).

Minsky, H. P. (1982) Can It Happen Again? Essays on Instability and Finance, 1st edition Oxford, Routledge.
Newey W.K. ve K.D. West (1987) "A Simple, Positive Semi-Definite, Heteroskedasticity and Autocorrelation Consistent Covariance Matrix" Econometrica 55(3): 703-708

Ocampo, J.A. (2003). Capital Account and CounterCyclical Prudential Regulation in Developing Countries içinde From Capital Surges to Drought: Seeking Stability for Emerging Markets. R. French-Davis and S. GriffithJones edition, Palgrave Macmillan, London: 217-244

Ordóñez, M,F. (2009) "Procyclicality in the Banking Activity" Conference on Procyclicality and the Role of Financial Regulation organized by Bank of Spain and the Financial Stability Institute.

Padoa-Schioppa, T. (2003) "Central Banks and Financial Stability: Exploring the Land in Between in the Transmission of the European Financial System" Second ECB Central Banking Conference, Frankfurt.

Persaud, A. (2003) Market Liquidity and Risk Management içinde Liquidity Black Holes: Understanding, Quantifying and Managing Financial Liquidity Risk, A. Persaud edition, London, Risk Books.

Schinasi, G.J. (2004) Safeguarding Financial Stability, Theory and Practice, Washington, IMF Publushing

Stiglitz, J. (2001) "Principles of Financial Regulation: A Dynamic Approach" The World Bank Observer 16(1): 1-18

Tunay, K. B. (2014) Ekonomik Döngüler, Krizler Durgunluklar ve Türkiye'ye Dair Tespitler, Nobel Ekonomik Yayıncılık, İstanbul

Zachary, F., Rudloff, B. ve Weber, S. (2015) "Measures of Systemic Risk" Cornell University Library, Februray. https://arxiv.org/pdf/1502.07961v4.pdf. (01.06.2016) 